\title{
Association of deranged cerebrovascular reactivity with brain injury following cardiac arrest: a post-hoc analysis of the COMACARE trial
}

Johanna Laurikkala ${ }^{1 *} \mathbb{D}$, Anders Aneman ${ }^{2,3,4}$, Alexander Peng ${ }^{2}$, Matti Reinikainen ${ }^{5}$, Paul Pham ${ }^{6}$, Pekka Jakkula ${ }^{1}$, Johanna Hästbacka', Erika Wilkman', Pekka Loisa7, Jussi Toppila ${ }^{8}$, Thomas Birkelund ${ }^{9}$, Kaj Blennow ${ }^{10,11}$, Henrik Zetterberg ${ }^{10,11,12,13}$ and Markus B. Skrifvars ${ }^{14}$

\begin{abstract}
Background: Impaired cerebrovascular reactivity (CVR) is one feature of post cardiac arrest encephalopathy. We studied the incidence and features of CVR by near infrared spectroscopy (NIRS) and associations with outcome and biomarkers of brain injury.

Methods: A post-hoc analysis of 120 comatose OHCA patients continuously monitored with NIRS and randomised to low- or high-normal oxygen, carbon dioxide and mean arterial blood pressure (MAP) targets for $48 \mathrm{~h}$. The tissue oximetry index $\left(\mathrm{TO}_{x}\right)$ generated by the moving correlation coefficient between cerebral tissue oxygenation measured by NIRS and MAP was used as a dynamic index of CVR with $\mathrm{TO}_{x}>0$ indicating impaired reactivity and $\mathrm{TO}_{\mathrm{x}}>0.3$ used to delineate the lower and upper MAP bounds for disrupted CVR. TO $x$ was analysed in the 0-12, 12-24, 24-48 h timeperiods and integrated over $0-48 \mathrm{~h}$. The primary outcome was the association between $\mathrm{TO}_{x}$ and six-month functional outcome dichotomised by the cerebral performance category (CPC1-2 good vs. 3-5 poor). Secondary outcomes included associations with MAP bounds for CVR and biomarkers of brain injury.

Results: In 108 patients with sufficient data to calculate $\mathrm{TO}_{x^{\prime}} 76$ patients (70\%) had impaired CVR and among these, chronic hypertension was more common (58\% vs. 31\%, $p=0.002$ ). Integrated $\mathrm{TO}_{x}$ for $0-48 \mathrm{~h}$ was higher in patients with poor outcome than in patients with good outcome $(0.8995 \% \mathrm{Cl}$ [ -1.17 to 2.94$]$ vs. $-2.7195 \% \mathrm{Cl}[-4.16$ to -1.26$], p=0.05)$. Patients with poor outcomes had a decreased upper MAP bound of CVR over time $(p=0.001)$, including the high-normal oxygen $(p=0.002)$, carbon dioxide $(p=0.012)$ and MAP $(p=0.001)$ groups. The MAP range of maintained CVR was narrower in all time intervals and intervention groups $(p<0.05)$. NfL concentrations were higher in patients with impaired CVR compared to those with intact CVR (43 IQR [15-650] vs 20 IQR [13-199] pg/ml, $p=0.042$ ).
\end{abstract}

\footnotetext{
*Correspondence: johanna.laurikkala@hus.fi

${ }^{1}$ Department of Anaesthesiology, Intensive Care and Pain Medicine,

University of Helsinki and Helsinki University Hospital, Meilahden

SairaalaHaartmaninkatu 4, 000290 Helsinki, Finland

Full list of author information is available at the end of the article
} permits use, sharing, adaptation, distribution and reproduction in any medium or format, as long as you give appropriate credit to the original author(s) and the source, provide a link to the Creative Commons licence, and indicate if changes were made. The images or other third party material in this article are included in the article's Creative Commons licence, unless indicated otherwise in a credit line to the material. If material is not included in the article's Creative Commons licence and your intended use is not permitted by statutory regulation or exceeds the permitted use, you will need to obtain permission directly from the copyright holder. To view a copy of this licence, visit http://creativecommons.org/licenses/by/4.0/. The Creative Commons Public Domain Dedication waiver (http://creativeco mmons.org/publicdomain/zero/1.0/) applies to the data made available in this article, unless otherwise stated in a credit line to the data. 
Conclusion: Impaired CVR over $48 \mathrm{~h}$ was more common in patients with chronic hypertension and associated with poor outcome. Decreased upper MAP bound and a narrower MAP range for maintained CVR were associated with poor outcome and more severe brain injury assessed with NfL.

Trial registration ClinicalTrials.gov, NCT02698917.

Keywords: Cerebrovascular reactivity, Out-of-hospital cardiac arrest, Hypoxic-ischaemic brain injury

\section{Background}

Out-of-hospital cardiac arrest (OHCA) carries a high overall mortality rate related to hypoxic-ischaemic brain injury (HIBI) [1]. On suggested mechanism of HIBI is ongoing cerebral hypoxia related to insufficient cerebral blood flow (CBF) after return of spontaneous circulation (ROSC) [2-6]. Cerebrovascular reactivity (CVR) refers to the ability of the brain vasculature to change flow resistance in response to fluctuating blood tension of oxygen and carbon dioxide and varying mean arterial blood pressure (MAP) levels, aiming to maintain a relatively constant CBF [7, 8]. The specific aspect of CVR related to MAP is commonly referred to as cerebral autoregulation. Near-infrared spectroscopy (NIRS) may be used to monitor spontaneous low-frequency oscillations in cerebral tissue oxygenation $\left(\mathrm{cStO}_{2}\right)$ that reflect $\mathrm{CBF}$ and, when correlated with simultaneous changes in MAP, allow for the tissue oxygenation index $\left(\mathrm{TO}_{\mathrm{x}}\right)$ to be derived as an index of dynamic CVR. This technique has known limitations but provides a non-invasive method to estimate CVR at the bedside [9-12]. Impaired CVR monitored by $\mathrm{TO}_{\mathrm{x}}$ is associated with poor neurological outcomes in acute neurocritical conditions $[13,14]$ and in OHCA, as suggested by smaller, single-centre, observational cohort studies $[4,5,15]$.

In the multicentre randomised controlled pilot study COMACARE, 120 adult comatose mechanically ventilated survivors of OHCA with an initial rhythm of ventricular fibrillation/tachycardia were treated with low- or high-normal targets for MAP, arterial oxygen $\left(\mathrm{P}_{\mathrm{a}} \mathrm{O}_{2}\right)$ and carbon dioxide $\left(\mathrm{P}_{\mathrm{a}} \mathrm{CO}_{2}\right)$ tension [16]. All patients were monitored with the same type of NIRS device over the first $48 \mathrm{~h}$ of ICU care enabling an estimation of CVR over time. The primary outcome in this post-hoc analysis was the association between TOx and six-month neurological outcome dichotomised by cerebral performance category (CPC1-2 good vs. 3-5 poor), and we hypothesised that CVR would be impaired in patients with poor outcome.

\section{Methods}

\section{Setting and participants}

Six ICUs in Finland and one in Denmark participated in the COMACARE study that was conducted from March 2016 to March 2017. The study protocol and main results have been published earlier [16-18]. Briefly, the study included 120 comatose, mechanically ventilated survivors resuscitated from witnessed OHCA with ventricular tachycardia or fibrillation as the initial rhythm. The trial used a $2^{3}$ factorial design where each patient was randomised into one of eight arms, each having a different combination of targets: a low-normal $(65-75 \mathrm{mmHg})$ or high-normal (80-100 mmHg) MAP, a normal (10$15 \mathrm{kPa}$ ) or moderately elevated $(20-25 \mathrm{kPa}) \mathrm{P}_{\mathrm{a}} \mathrm{O}_{2}$ and a low-normal $(4.5-4.7 \mathrm{kPa})$ or high-normal $(5.8-6.0 \mathrm{kPa})$ $\mathrm{P}_{\mathrm{a}} \mathrm{CO}_{2}$. All patients were treated with targeted temperature management at either $33^{\circ} \mathrm{C}$ or $36^{\circ} \mathrm{C}$, and all patients had invasive blood pressure monitoring. The protocol for this post-hoc analysis was published prior to commencing the study [19].

\section{Patient data and monitoring of cerebrovascular reactivity}

Patient demographics, cardiac arrest and resuscitation characteristics, ICU acuity (APACHE II) and treatment factors were captured. The $\mathrm{CStO}_{2}$ was measured using the INVOS 5100C monitor (Covidien Company, USA) with two skin sensors attached bilaterally to the patient's forehead, avoiding the frontal sinuses and temporal muscles. The mean values of the left and right hemispheric $\mathrm{cStO}_{2}$ values were used to calculate the $\mathrm{TO}_{\mathrm{x}}$ as a moving Pearson correlation coefficient in the time domain between $10 \mathrm{~min}$ averages of $\mathrm{MAP}$ and $\mathrm{cStO}_{2}$ using the $\mathrm{ICM}+$ Brain Monitoring software (Version 8.3, University of Cambridge) [9]. $\mathrm{A} \mathrm{TO}_{\mathrm{x}}$ within the -1 to 0 range was used to indicate maintained CVR, and a $\mathrm{TO}_{x}$ from $>0$ to 1 indicated impaired CVR. Mean $\mathrm{TO}_{\mathrm{x}}$ values were derived for three time periods: $0-12 \mathrm{~h}, 12-24 \mathrm{~h}$ and 24-48 h. The $\mathrm{TO}_{\mathrm{x}}$ values were subsequently divided into MAP bins of $5 \mathrm{mmHg}$ and fitted to a second-order polynomial with its nadir determining the optimal observed $\mathrm{TO}_{\mathrm{x}}\left(\mathrm{OptTO}_{\mathrm{x}}\right)$ [20]. The OptMAP was determined as the MAP corresponding to the OptTO $\mathrm{T}_{\mathrm{x}}$ on the fitted curve. The MAP intersecting a $\mathrm{TO}_{\mathrm{x}}$ threshold of 0.30 on the second-order polynomial fit was calculated for each patient to represent the lower and upper bounds of MAP for maintained CVR and the range of MAP with maintained CVR calculated as the difference [19]. The nomenclature cerebrovascular reactivity rather than cerebral autoregulation is used throughout this paper to reflect the concomitant MAP, $\mathrm{PaO} 2$ and $\mathrm{PaCO} 2$ targets studied. 


\section{Biomarkers of brain injury}

Serum samples were collected at $48 \mathrm{~h}$ after OHCA and concentrations of neuron specific enolase (NSE), the astrocytic calcium-binding protein S100B and neurofilament light (NfL) were measured as previously described [21].

\section{Neurological outcome}

An independent neurologist blinded to the study interventions evaluated the patients' functional outcomes six months after OHCA. Neurological outcomes were assessed according to Pittsburgh Cerebral Performance Categories (CPC) [22]. Good outcome was defined as CPC 1-2 (good cerebral performance or moderate cerebral disability) and poor outcome as CPC 3-5 (severe cerebral disability, coma/vegetative state or death).

\section{Study outcomes}

The primary outcome was the association between impaired CVR as determined by TOx and neurological outcome. The secondary outcomes were associations between CVR characteristics (OptTOx, OptMAP, the upper and lower MAP bounds as well as the MAP range for maintained CVR) and neurological status and biomarkers of brain injury. The primary and secondary outcomes were stratified by the MAP, $\mathrm{PaO} 2$ and $\mathrm{PaCO} 2$ targets according to the COMACARE study design. We also explored factors associated with impaired CVR including patient, resuscitation and ICU admission characteristics.

\section{Statistical methods}

Categorical data are presented as counts and percentages and compared with the chi-square test. Continuous data are presented as medians with interquartile ranges (IQR) and compared with the Mann-Whitney U-test. We performed a univariable analysis to determine possible risk factors for impaired CVR defined as $\mathrm{TO}_{\mathrm{x}}>0$ and poor neurological outcome. We calculated the time-integrated area below $\mathrm{OptTO}_{\mathrm{x}}$ and OptMAP and outside the upper and lower MAP bounds for maintained CVR as well as the MAP range ( $\mathrm{mmHg}$ min). Both the mean TOx in the separate time periods and integrated over $0-48 \mathrm{~h}$ were evaluated. Comparisons of $\mathrm{TO}_{x}, \mathrm{OptTO}_{x}$, OptMAP, MAP bounds and range for maintained CVR in the time periods $0-12 \mathrm{~h}, 12-24 \mathrm{~h}$ and $24-84 \mathrm{~h}$ between outcome groups were performed using mixed linear model analyses. We constructed multivariable models including age, sex, time to ROSC and hypertension as factors likely to influence CVR. All statistical analyses were performed using SPSS 25 (IBM, Armonk, NY, USA) or GraphPad PRISM (version 7.0d for MacOSX, GraphPad Software,
La Jolla, CA, USA). A $p$ value $<0.05$ was considered statistically significant.

\section{Results}

From the main COMACARE study, we excluded 12 survivors with incomplete registrations of MAP or $\mathrm{CStO}_{2}$ data. A flowchart of study patients is presented in Fig. 1. Of the 108 OHCA patients, 32 had intact and 76 had impaired CVR. Baseline characteristics, cardiac arrest and resuscitation factors, medical history and ICU care indexed by whether the CVR was maintained or not are presented in Table 1. Patients with chronic hypertension were more likely to have impaired CVR $(57.9 \%$ vs $31.3 \%$, $p=0.012$ ). In a multivariable model including age, gender and time to ROSC, chronic hypertension (OR 2.95, 95\% CI $[1.16,7.51], p=0.024)$ was the only independent predictor of impaired CVR.

\section{Markers of cerebrovascular reactivity}

The primary outcome i.e. the comparison of changes in CVR assessed by TOx against neurological outcome are shown in Table 2 . The primary outcome variable mean TOx was higher in patients with poor functional outcome when analysed with mixed linear analysis $(p=0.004)$. In addition, the cumulative time-integrated "AUROC" TOx $(0-48 \mathrm{~h})$ was higher in patients with poor neurological outcome than in those with good outcome (0.89 (95\% CI [- 1.17; 2.94] vs - 2.71 (95\% CI [- 4.16; $1.26], p=0.05)$.

With regard to the secondary outcomes, the mean TOx, OptTO ${ }_{x}$ OptMAP, upper and lower MAP bounds and MAP range for maintained CVR in patients for time periods $0-12 \mathrm{~h}, 12-24 \mathrm{~h}$ and $24-48 \mathrm{~h}$ are reported in Table 2. Patients with poor neurological function had a decreased upper MAP bound for maintained CVR compared to patients with good neurological function in all time intervals in the mixed linear model analysis $(p=0.001)$ (Table 2). In the intervention groups, the upper MAP bound for maintained CVR was significantly decreased during all three time periods in patients with poor neurological outcomes compared to patients with good outcomes in the high-normal $\mathrm{P}_{\mathrm{a}} \mathrm{CO}_{2}(p=0.012)$, high $\mathrm{P}_{\mathrm{a}} \mathrm{O}_{2}(p=0.002)$ and high-normal MAP $(p=0-001)$ groups (Additional file 1: Table S1). The MAP range of maintained CVR was narrower in patients with poor outcomes in all three time periods in the mixed linear analysis $(p<0.001)$ (Table 2$)$. We found no difference in $\mathrm{OptTO}_{x}$, lower MAP bound and OptMAP between patients with good or poor outcomes (Table 2). 


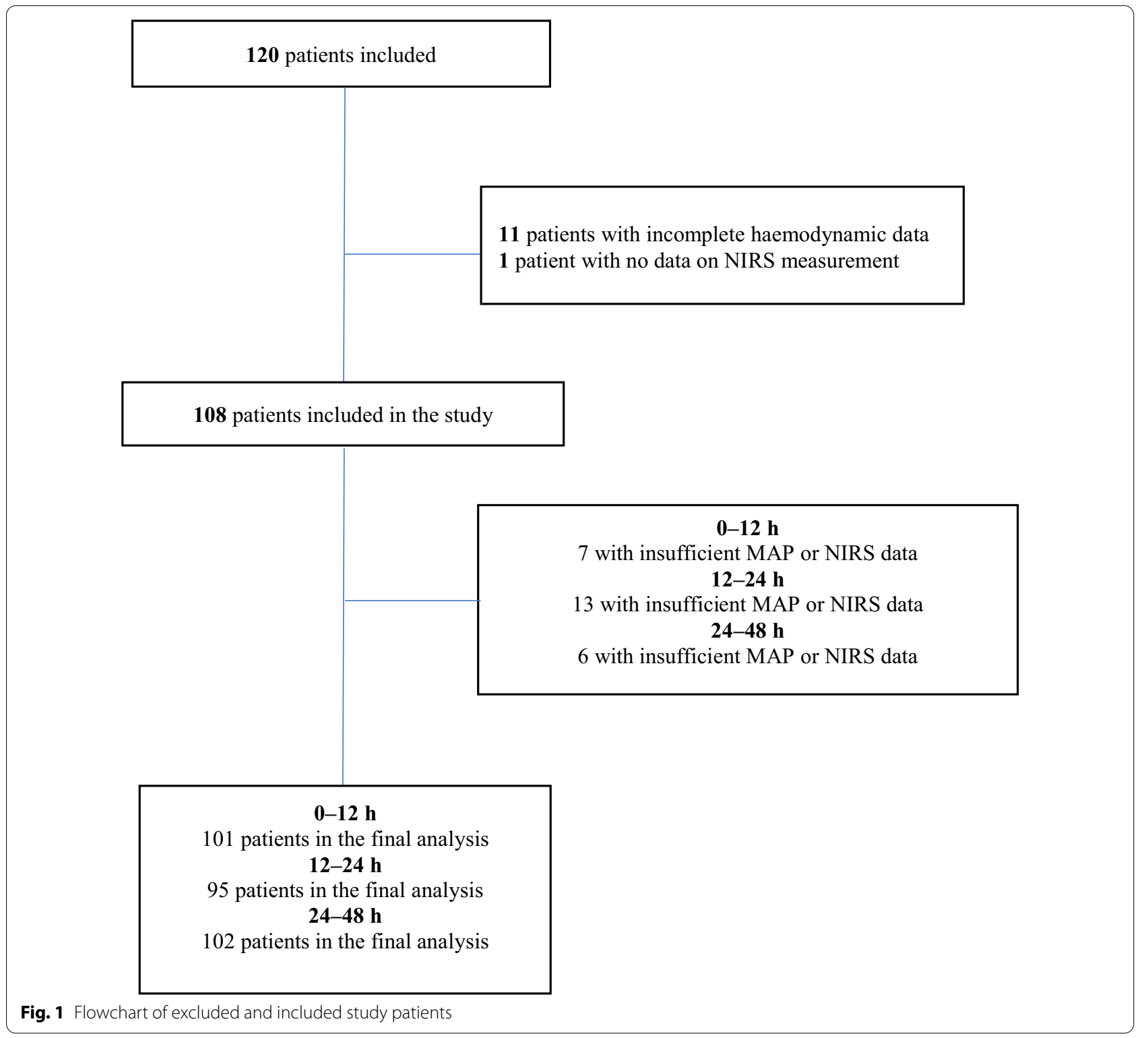

Time-integrated mean arterial pressure area between, below and above the bounds for maintained cerebrovascular reactivity

There were no statistically significant differences in the MAP areas between the lower and upper MAP bounds for maintained CVR nor below the lower MAP bound or above the upper MAP bound comparing patients with good or poor long-term outcomes (Table 3). Also, MAP areas were explored within all treatment arms (Additional file 1: Table S2). The MAP area below the lower MAP bound for maintained CVR was larger in the low $\mathrm{P}_{\mathrm{a}} \mathrm{CO}_{2}$ group during the time periods $12-24 \mathrm{~h}$ and $24-48 \mathrm{~h}(p=0.024)$ (Additional file 1: Table S2). Patients in the high MAP group had a larger MAP area below the lower MAP bound for maintained CVR during the time periods $0-12 \mathrm{~h}$ and $12-24 \mathrm{~h}(p=0.021)$ (Additional file 1: Table S2). A comparison of optimal MAP groups in all time periods, $0-12 \mathrm{~h}, 12-24 \mathrm{~h}$ and $24-48 \mathrm{~h}$, is shown in Fig. 2.

\section{NSE, S100B and NfL and cerebrovascular reactivity}

Biomarker concentrations $48 \mathrm{~h}$ after $\mathrm{OHCA}$ versus CVR are illustrated in Fig. 3. The NfL concentration was higher in patients with impaired CVR compared with those with maintained CVR (43.0 [inter-quartile range, 15.2-650.3] $\mu \mathrm{g} / \mathrm{L}$ vs. 20.4 [13.0-199.3] $\mu \mathrm{g} / \mathrm{L})$. A mixed linear model of NfL levels over time in patients 
Table 1 Patient characteristics with maintained $(\mathrm{TOx}<0)$ or impaired (TOx $>0)$ cerebrovascular reactivity $(C V R)$

\begin{tabular}{|c|c|c|c|c|c|}
\hline Characteristic & Data available & $\begin{array}{l}\text { All } \\
n=108\end{array}$ & $\begin{array}{l}\text { Maintained CVR } \\
\mathrm{n}=32\end{array}$ & $\begin{array}{l}\text { Impaired CVR } \\
\mathrm{n}=76\end{array}$ & $p$-value \\
\hline Gender, n\% (male) & 108 & $90(83.3 \%)$ & $24(75.0 \%)$ & $66(73.3 \%)$ & 0.133 \\
\hline Age, years & 108 & $61.0(53.0-70.0)$ & $55.0(44.5-69.0)$ & $61.0(53.0-66.3)$ & 0.057 \\
\hline $\mathrm{BMl}$ & 106 & $26.3(23.4-29.4)$ & $26.3(24.2-28.6)$ & $26.1(23.3-29.4)$ & 0.866 \\
\hline Neurologic function before cardiac arrest & 108 & & & & 0.950 \\
\hline Normal, CPC1, n (\%) & & $101(93.5 \%)$ & $30(93.8 \%)$ & $71(93.4 \%)$ & \\
\hline Some disability, CPC2, n (\%) & & $7(6.5 \%)$ & $2(6.3 \%)$ & $5(6.6 \%)$ & \\
\hline \multicolumn{6}{|c|}{ Cardiac arrest characteristics and resuscitation factors } \\
\hline Bystander CPR or compressions only, n (\%) & 108 & $88(81.5 \%)$ & $25(78.1 \%)$ & $63(82.9 \%)$ & 0.564 \\
\hline Initial rhythm & 108 & & & & 0.359 \\
\hline$V F, n(\%)$ & & $106(98.1 \%)$ & $32(100.0 \%)$ & $74(97.4 \%)$ & \\
\hline VT, n (\%) & & $2(1.9 \%)$ & $0(0 \%)$ & $2(2.6 \%)$ & \\
\hline Time to $B L S$, min & 106 & $7.0(6.0-9.0)$ & $7.0(6.0-10.0)$ & $8.0(6.0-9.3)$ & 0.813 \\
\hline Time to ALS, min & 106 & $10.0(8.0-12.0)$ & $9.0(7.5-12.0)$ & $10.0(8.0-12.0)$ & 0.643 \\
\hline Time to ROSC, min & 106 & $21.0(16.0-25.0)$ & $17.7(15.5-25.0)$ & $18.8(14.1-24.5)$ & 0.197 \\
\hline GCS after ROSC & 99 & $3.0(3.0-3.0)$ & $3.0(3.0-4.5)$ & $3.0(3.0-3.3)$ & 0.093 \\
\hline \multicolumn{6}{|l|}{ Medical history } \\
\hline IHD (NYHA class IV), n (\%) & 107 & $2(1.9 \%)$ & $0(0 \%)$ & $2(2.7 \%)$ & 0.353 \\
\hline HTA, n (\%) & 108 & $54(50.0 \%)$ & $10(31.3 \%)$ & $44(57.9 \%)$ & 0.012 \\
\hline Smoker, n (\%) & 95 & $32(33.7 \%)$ & $10(37.0 \%)$ & $22(32.4 \%)$ & 0.665 \\
\hline \multicolumn{6}{|l|}{ Treatment } \\
\hline PCI before ICU admission & 108 & $53(49.1 \%)$ & $14(43.8 \%)$ & $39(51.3 \%)$ & 0.477 \\
\hline \multicolumn{6}{|l|}{ Severity of illness score } \\
\hline Apache II & 108 & $27.0(24.0-30.0)$ & $27.0(24.0-29.0)$ & $27.0(24.0-31.3)$ & 0.119 \\
\hline Targeted temperature management & 108 & & & & 0.140 \\
\hline $33^{\circ} \mathrm{C}, \mathrm{n}(\%)$ & & $77(71.3 \%)$ & $26(34.0 \%)$ & $51(66.0 \%)$ & \\
\hline $36^{\circ} \mathrm{C}, \mathrm{n}(\%)$ & & $31(28.7 \%)$ & $6(20.0 \%)$ & $25(80.0 \%)$ & \\
\hline EEG - beginning POOR & 107 & $81(75.7 \%)$ & $24(77.4 \%)$ & $57(75.0 \%)$ & 0.794 \\
\hline $\mathrm{EEG}$ - end POOR & 107 & $36(33.6 \%)$ & $9(29.0 \%)$ & $27(35.5 \%)$ & 0.523 \\
\hline Brain oedema, NO & 108 & $108(100 \%)$ & $32(100 \%)$ & $76(100 \%)$ & \\
\hline Duration of mechanical ventilation, hours & 80 & $70.5(49.5-95.2)$ & $70.5(49.1-90.5)$ & $63.1(49.2-95.1)$ & 0.637 \\
\hline Length of stay in ICU, hours & 104 & $103.0(76.6-145.9)$ & $107.0(78.5-132.0)$ & $92.30(75.0-141.0)$ & 0.575 \\
\hline Mortality $30 \mathrm{~d}$ & 108 & $33(30.6 \%)$ & $8(25.0 \%)$ & $25(32.9 \%)$ & 0.418 \\
\hline CPC 6 months, poor & 108 & $35(32.4 \%)$ & $9(28.1 \%)$ & $26(34.2 \%)$ & 0.539 \\
\hline
\end{tabular}

Numbers are median (interquartile range) or $\mathrm{n}$ (percentage)

CVR cerebrovascular reactivity, BMI body mass index $\left(\mathrm{kg} / \mathrm{m}^{2}\right), B L S$ basic life support, $A L S$ advanced life support, GCS Glasgow coma scale, ROSC return of spontaneous circulation, IHD ischemic heart disease, HTA arterial hypertension, $\mathrm{PCl}$ percutaneous coronary intervention

with maintained or impaired CVR showed a statistically significant difference $(p=0.042)$. No significant differences in the median serum NSE or S100B concentrations were found after $48 \mathrm{~h}$ in OHCA patients based on whether they had maintained or impaired CVR (Fig. 3).

The analysis of all biomarkers at $48 \mathrm{~h}$ indexed by whether CVR was maintained or impaired in the different study time periods indexed by intervention groups is reported in Additional file 1: Table S3 and S4. Biomarkers of brain injury were increased in patients with impaired CVR in all intervention groups during the first $12 \mathrm{~h}$ but not at later time points.

\section{Discussion}

In this post-hoc analysis of the COMACARE study cohort focusing on cerebrovascular reactivity (CVR), a majority of patients had impaired reactivity as assessed by the tissue oxygenation index (TOx), most commonly in patients with chronic hypertension. The TOx was higher, consistent with impaired CVR, in patients with poor neurological outcome over the whole time period 
Table 2 Mixed linear model analysis for Mean TOx, OptTOx, OptMAP, upper and lower MAP bounds and MAP range for maintained CVR in three time periods: $0-12 \mathrm{~h}, 12-24 \mathrm{~h}$ and $24-48 \mathrm{~h}$

\begin{tabular}{|c|c|c|c|c|c|}
\hline & Group & $0-12 \mathrm{~h}$ & $12-24 \mathrm{~h}$ & $24-48 \mathrm{~h}$ & $p$-value \\
\hline \multirow[t]{2}{*}{ Mean TOx } & Poor outcome & $0.06(-0.07$ to 0.14$)$ & $-0.03(-0.11$ to 0.16$)$ & $0.01(-0.09$ to 0.14$)$ & 0.004 \\
\hline & Good outcome & $-0.04(-0.12$ to 0.04$)$ & $-0.05(-0.21$ to 0.05$)$ & $-0.02(-0.10$ to 0.06$)$ & \\
\hline \multirow[t]{2}{*}{ OptTOx } & Poor outcome & $-0.21(-0.35$ to -0.02$)$ & $-0.17(-0.36$ to -0.02$)$ & $-0.19(-0.36$ to -0.05$)$ & 0.077 \\
\hline & Good outcome & $-0.24(-0.38$ to -0.14$)$ & $-0.27(-0.48$ to -0.10$)$ & $-0.23(-0.37$ to -0.11$)$ & \\
\hline \multirow[t]{2}{*}{ OptMAP } & Poor outcome & $79.7(73.5-87.8)$ & $76.4(71.1-81.7)$ & $81.7(72.4-88.3)$ & 0.079 \\
\hline & Good outcome & $80.9(71.4-86.7)$ & $81.7(73.0-87.4)$ & $82.7(75.0-87.4)$ & \\
\hline \multirow[t]{2}{*}{ Upper MAP bound } & Poor outcome & $90.5(81.1-98.4)$ & $89.5(80.6-92.9)$ & $92.8(83.4-100.3)$ & 0.001 \\
\hline & Good outcome & $94.7(85.4-102.3)$ & $93.4(83.2-100.4)$ & $94.4(89.0-101.0)$ & \\
\hline \multirow[t]{2}{*}{ Lower MAP bound } & Poor outcome & $69.6(64.2-74.4)$ & $66.2(63.0-73.1)$ & $68.5(63.4-74.4)$ & 0.569 \\
\hline & Good outcome & $68.0(63.3-75.9)$ & $69.7(62.1-74.7)$ & $68.4(63.6-73.5)$ & \\
\hline \multirow[t]{2}{*}{ MAP range } & Poor outcome & $19(15-30)$ & $24(17-26)$ & $23(17-29)$ & $<0.001$ \\
\hline & Good outcome & $28(23-36)$ & $25(20-36)$ & $33(25-39)$ & \\
\hline
\end{tabular}

$p$ values are comparing good versus poor neurologic outcome

Values are expressed as medians (interquartile ranges)

OptTOx optimal tissue oxygenation index

OptMAP optimal mean arterial pressure

Table 3 Mixed linear analysis for time-integrated mean arterial pressure (MAP) area (mmHg min) between the lower and upper MAP bounds for maintained cerebrovascular reactivity (CVR) and total MAP area below the lower and above the upper MAP bound for maintained CVR stratified by the factorial design groups during three time periods: $0-12$ h, 12-24 h and 24-48 h, with good or poor neurologic outcomes

$\begin{array}{llll}0-12 h & 12-24 h & 24-48 h & p \text {-value }\end{array}$

MAP area between lower and upper MAP bounds, $\mathrm{mmHg}$ min

All patients

Good outcome

Poor outcome

MAP area below lower MAP bound, $\mathrm{mmHg}$ min

All patients

Good outcome

Poor outcome

MAP area above upper MAP bound, $\mathrm{mmHg}$ min

All patients

Good outcome

Poor outcome

Values are expressed

$\begin{array}{llll}5399(3950-8231) & 7958(4818-11079) & 15870(9423-21785) & \\ 6900(4849-8880) & 8389(5166-11479) & 17277(10180-22792) & 0.246 \\ 5542(3292-6903) & 6134(3500-9262) & 12139(6305-16794) & \\ 132(36-479) & 107(31-305) & 235(6-653) & \\ 118(33-358) & 103(28-319) & 235(54-503) & 0.061 \\ 150(46-502) & 134.6(54.2-358.3) & 197(85-1153) & \\ & & & \\ 315(100-846) & 195(55-1004) & 266(99-101) & 0.243 \\ 319(96-800) & 135(28-338) & 222(79-1011) & \\ 314(108-1369) & 253(64-10492) & 339(149-1010) & \end{array}$

studied (0-48 h) but not in the isolated 12-24 h intervals. Patients with poor neurological outcome had a decreased upper MAP bound and a narrower MAP range for maintained CVR but there was no difference in the lower MAP bound. The decreased upper MAP bound for maintained CVR in patients with poor outcome was observed in patients treated with a higher rather than lower oxygen, carbon dioxide and MAP targets when the subgroups were studied separately. Patients with impaired
CVR had increased levels of the brain injury biomarker NfL but not NSE or S100b.

The importance of optimising cerebral oxygen delivery to mitigate hypoxic-ischaemic brain injury is supported by observational data that include strategies of augmented MAP to ameliorate ongoing cerebral ischemia in patients after cardiac arrest [6]. Previous smaller studies have demonstrated that impaired CVR is associated with hypoxic-ischaemic brain injury and poor neurological 

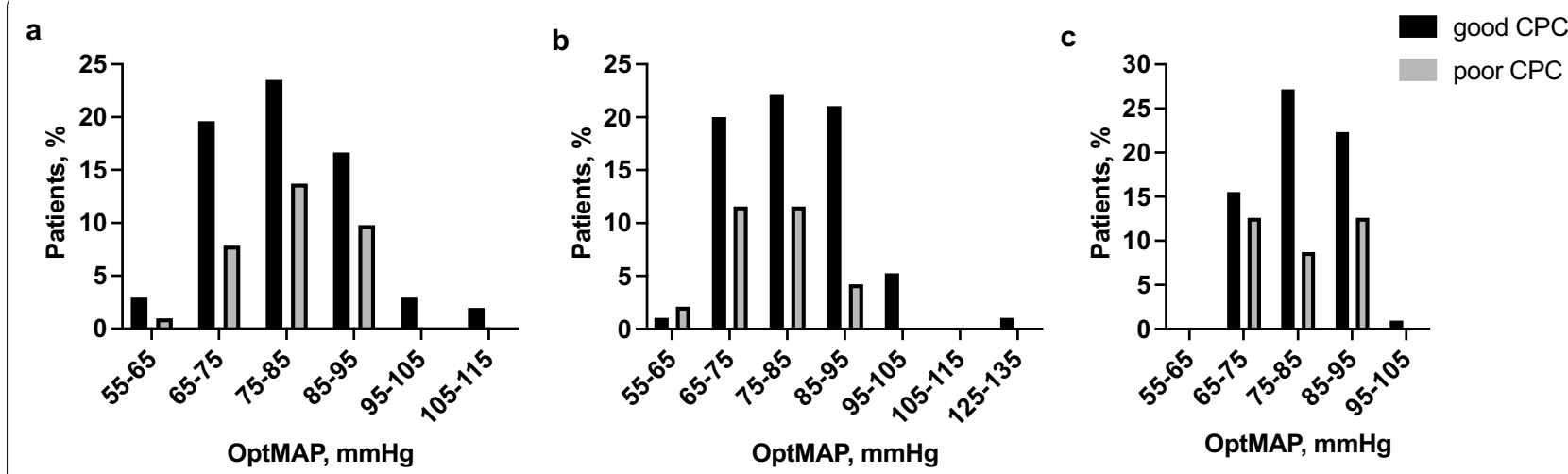

Fig. 2 Optimal MAP (OptMAP) in three time periods: a 0-12 h, b 12-24 h and c 24-48 h, with good or poor six-month neurologic outcomes

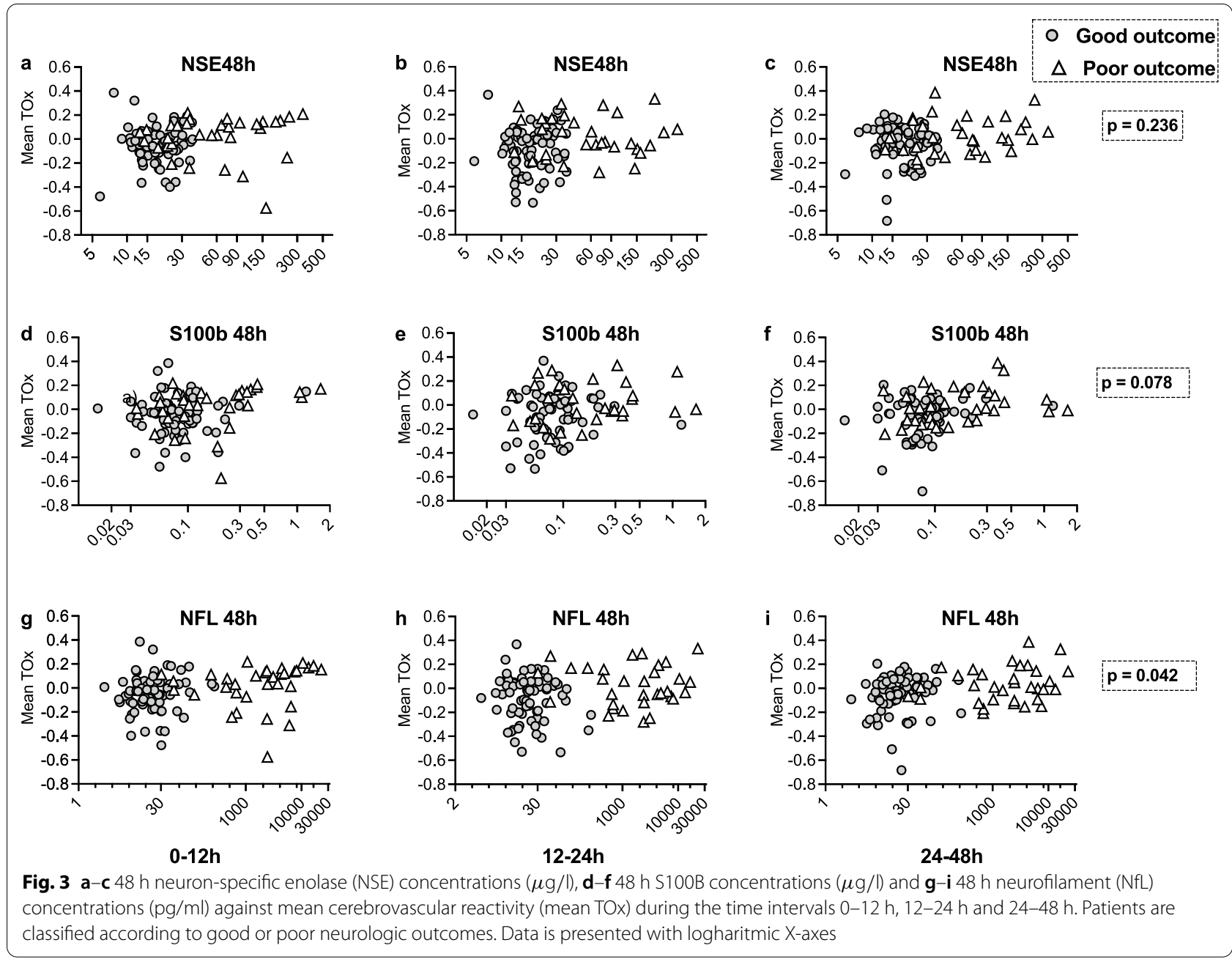

outcomes following cardiac arrest (CA) [4, 5, 15]. Regulatory interdependence between MAP and arterial blood gases provides synergistic effects on $\mathrm{CBF}$ and underpins the rationale of this post-hoc analysis. While the TOx in the isolated time periods studied was not statistically different between patients with good and poor neurological outcomes, the time-integrated TOx was higher consistent with impaired CVR in patients with poor 
neurology. Ameloot et al. [13] studied 51 comatose survivors of non-traumatic CA treated with target temperature management (TTM) at $33^{\circ} \mathrm{C}$ for $24 \mathrm{~h}$ and reported impaired CVR in $35 \%$ of the patients using the same cutoff for the slope of the cStO2/MAP correlation $(>0)$ as used in this study. Pham et al. [12], using a similar $\mathrm{TO}_{x}$ definition for impaired CVR, reported an incidence rate of 15/23 (65\%) in comatose survivors of CA of cardiac origin, which is very similar to the proportion found in the present study, which comprised almost five times as many subjects. Sekhon et al. [14] performed a feasibility study of $\mathrm{TO}_{\mathrm{x}}$ in 20 cardiac arrest patients and reported impaired CVR in $15 \%$ of all individual measurements using a higher threshold at $\mathrm{TO}_{\mathrm{x}}>0.3$. Both Ameloot et al. and Pham et al. demonstrated an association between CVR and clinical outcomes, either as the odds' ratio for survival in a good neurological state in patients with maintained CVR (4.62 [1.06-20.1]) [5] or as the odds ratio for survival in patients with impaired CVR $(0.15$ [0.01-0.50]) [4]. The variability in CBF attributable to changes in MAP may be limited in critically ill patients [23] hence disrupting the coherence of vascular pressure reactivity to assess CVR. This could explain the lack of association between TOx in isolated time periods and neurological outcomes while the time-integrated TOx might represent a more robust measure of CVR after CA. These findings indicate that the duration of data capture warrants careful consideration in the design of any TOx guided interventional studies in CA patients as the most beneficial time for monitoring and therapy remain to be established. Both age and chronic hypertension demonstrated an independent association with impaired CVR in this study that is aligned with the higher frequency of disturbed CVR reported by Ameloot et al. [13] in patients with chronic hypertension. The importance of CVR is further highlighted by the increased NfL levels in patients with impaired CVR, indicating a more severe brain injury when CVR is attenuated.

Overall, cerebrovascular reactivity and the factors affecting it are regrettably still poorly known [24]. Previously, modification and optimization of CVR in brain injury and ICH by altering blood pressure and ventilation have been described in the literature $[25,26]$. It has also been hypothesized that the brain endothelin systems could be used as therapeutic targets for improving CVR, as they are involved in both vasoconstriction and vasodilation of cerebral blood vessels, both key elements in CVR and also involved in pathologic processes leading to both ischemia and oedema in brain injuries [27]. The $\mathrm{TO}_{\mathrm{x}}$ analyses in this study allow for a more nuanced assessment of CVR capacity beyond a dichotomising threshold value. This includes the lower and upper MAP bounds and the range of MAP that delineates maintained CVR as well as the MAP associated with the lowest optimal $\mathrm{TO}_{\mathrm{x}}$. This study used a more conservative threshold of TOx at 0.3 to delineate the lower and upper MAP bounds $[12,15]$ compared to previous studies that used the transition from negative to positive $\mathrm{TO}_{x}[4,5]$. The upper MAP bound for maintained CVR was consistently lower in patients with poor neurological outcomes than in those with good outcomes in all time intervals, and this included all the $2^{3}$ factorial design groups with different targets for MAP, $\mathrm{PaO}_{2}$ and $\mathrm{PaCO}_{2}$. The upper MAP bound was high at $95-100 \mathrm{mmHg}$ in the whole study cohort, and while not statistically different by outcome in all intervention subgroups, the numerical contrasts were consistent. Furthermore, the MAP range for maintained CVR was narrower in patients with poor outcomes during all time intervals and in all subgroups of MAP, $\mathrm{P}_{\mathrm{a}} \mathrm{O}_{2}$ and $\mathrm{P}_{\mathrm{a}} \mathrm{CO}_{2}$. This is aligned with animal studies of increased intracranial pressure [28] or induced subarachnoidal haemorrhage [29] demonstrating decreased upper MAP bound and a narrower MAP range for CVR. It is furthermore supported by clinical data in postoperative cardiac surgical patients demonstrating that a decreased upper MAP bound and narrower range was associated with delirium in ICU [30] and studies in patients with traumatic brain injury showing that supra-optimal MAP was associated with worse neurological outcome [20, 31]. It is possible that the decreased upper MAP bound observed in this study was the result of increased intracranial pressure and/or transient hypoperfusion although this was not independently investigated. Taken together, these findings demonstrate a limited tolerability to MAP fluctuations in patients with an ultimately poor neurological outcome and suggest that a more individualised approach to MAP management after OHCA is needed [32]. Rather than presenting only a sensitivity to low MAP, this study indicates the need to limit excessively high MAP in patients with impaired CVR. This is not unexpected since the normal autoregulatory capacity of $\mathrm{CBF}$ is more efficacious at buffering increases in blood pressure $[7,33]$ suggesting the particular harm of high MAP when CVR is impaired.

Current guidelines on post-cardiac arrest care recommend targeting a MAP higher than $65 \mathrm{mmHg}$ and using adequate diuresis (more than $0.5 \mathrm{ml} / \mathrm{kg}$ ) and lactate clearance as a guide of adequate tissue perfusion [34]. The lower MAP bound for maintained CVR was very close to the $70 \mathrm{mmHg}$ reported in a recent review [35], albeit not statistically different between patients with good or poor outcomes. Importantly, the lower MAP bound was significantly higher [7] than classically suggested [36]. The most effective point of CVR, OptTOx, was numerically 
lower and the associated OptMAP numerically higher in patients with good compared to those with poor neurological outcome. However, this difference did not attain statistical significance $(p=0.08)$ in contrast to previous studies that demonstrated lower OptMAP in patients with good outcomes $[4,5]$. Ameloot et al. demonstrated that the time below the OptMAP was negatively associated with survival, although the effect estimate was moderate with an odds ratio of 0.97 (0.96-0.99) per \% of total study time. Differences in study design and analysis might explain these divergent results. This study captured data continuously over a longer period ( $48 \mathrm{~h}$ vs $24 \mathrm{~h}$ ) [5] and with considerably greater detail compared to the daily median of $81 \mathrm{~min}$ for the first three days [4]. Reports of a gradual return of $\mathrm{CBF}$ over $72 \mathrm{~h}$ after an initial reduction in the first $12 \mathrm{~h}$ of post-cardiac arrest [3, 37-39], with the present study encompassing a larger proportion of the latter phase, might confound comparisons to a dichotomous separation of outcomes dependent on the first $24 \mathrm{~h}$ of cerebral haemodynamics.

To answer the key question whether, and to what degree, cardiac arrest results in a disturbance in CVR requires an adequate control group. A previous pilot study demonstrated a lack of statistical difference between $\mathrm{TO}_{\mathrm{x}}$ during the first three days in post-cardiac arrest patients managed in the intensive care unit and healthy volunteers [12]. This type of comparison is challenged by the short period for measurements with rapid and marked changes, particularly increases, in MAP used to assess CVR $[4,40]$ in normal subjects. This is not likely to occur in sedated patients with extended monitoring and using protocolised titration to MAP targets. The CVR is more effective in buffering decreases in MAP that are more likely to occur in a population with acute cardiac dysfunction or as part of the post-cardiac arrest syndrome than increases in MAP [7]. Assessments of CVR are also dependent on the range and dynamics of MAP changes [33].

\section{Strengths and limitations}

Strengths of the current study include a pre-specified protocol for the analyses and a relatively large and homogeneous patient sample. The extended period of monitoring up to $48 \mathrm{~h}$ is likely to have captured all phases of post-cardiac arrest cerebral haemodynamics. Important limitations of NIRS and TOx to monitor CVR must be acknowledged. The use of NIRS to derive $\mathrm{TO}_{\mathrm{x}}$ as a measure of CVR is dependent on the correlation between $\mathrm{CStO}_{2}$ and $\mathrm{CBF}$, which might be variable [41]. Furthermore, different types of methods and mathematical approaches used to describe the CVR status, are still subject to several assumptions [42]. The use of NIRS for evaluation of CVR has nevertheless been widely studied and compared with these other metrics and with outcome in a large range of patient populations [13, 25, $43,44]$. In this study, resource use in the patients with intact and impaired CVR were not able to retrieve data on length of hospital stay and discharge destination even though this was included in the published protocol paper.

Perfusion pressure determined by MAP predominantly affects flow in the major cerebral arteries along with neurogenic control while other factors inherent to CVR such as blood $\mathrm{CO} 2$ and $\mathrm{O} 2$ tension, perivascular $\mathrm{pH}$ and metabolic neurovascular coupling affect the cerebral microcirculation at a level closer to the monitoring of cStO2 [7]. Barriers to oxygen diffusion after cardiac arrest may lead to dissociation between $\mathrm{CBF}$ and cStO2 [45]. The TOx variable has not been clinically validated in cardiac arrest patients but shows promise in patients at risk for adverse neurological events $[13,46,47]$ and correlates with other measures of CVR based on intracranial pressure monitoring or transcranial Doppler flowmetry [43, 46, 48, 49]. However the physiology of CVR is more complex than a simple linear correlation between MAP and CBF. Notably, the correlations between CVR and $\mathrm{P}_{\mathrm{a}} \mathrm{O}_{2}$ and $\mathrm{P}_{\mathrm{a}} \mathrm{CO}_{2}$ levels appear to have non-linear characteristics [7]. It is biologically plausible that considerable heterogeneity across the cerebral vasculature and the anatomical regions of the brain may exist that further confound assessments of CVR restricted to linear correlations or when a local cStO2 measurement is taken to represent global CBF. The numerical results for CVR may not be applicable to patients monitored with other NIRS equipment as proprietary algorithms and optode designs to avoid extracranial contamination of the signal [44] generate different results [40]. The retrospective, observational design of this study means that no causal inferences may be made, and the results should be viewed to demonstrate associations and generate hypotheses for future investigation with TOx a potential clinical heuristic [24]. Comparisons of CVR in the COMACARE study with a cohort of healthy volunteers, while intended in the published protocol [19], were abandoned because of significant and unreconcilable incongruities in monitoring time and resolution, NIRS equipment and the degree and origin of MAP variations. Resource use in the patients with intact and impaired CVR including length of mechanical ventilation and ICU stay were captured. We have compared and reported these in Table 1. We acknowledge that our protocol paper (1) also mentioned length of hospital stay in the hospital and discharge destination but unfortunately, we have not been able to retrieve this data reliably for all patients. 


\section{Conclusion}

Impaired CVR was common after cardiac arrest and occurred especially in patients with chronic hypertension. The tissue oxygenation index to assess CVR was only different between patients with good and poor neurological outcomes at six months when integrated over $48 \mathrm{~h}$ but not in shorter time periods. A decreased upper MAP bound and a narrower MAP range for maintained CVR was associated with poor neurological outcomes and impaired CVR was associated with higher levels of NfL, a novel marker of axonal brain injury.

\begin{abstract}
Abbreviations
OHCA: Out-of-hospital cardiac arrest; ROSC: Return of spontaneous circulation; MAP: Mean arterial pressure; NIRS: Near-infrared spectroscopy; $\mathrm{CStO}_{2}$ : Cerebral tissue oxygenation; $\mathrm{PaCO}_{2}$ : Arterial carbon dioxide tension; $\mathrm{PaO}_{2}$ : Arterial oxygen tension; TOx: Tissue oxygenation index; CVR: Cerebrovascular reactivity; OptTOx: Optimal cerebrovascular reactivity; OptMAP: Mean arterial pressure at optimal cerebrovascular reactivity; NSE: Neuron-specific enolase; NfL: Neurofilament light; APACHE II: Acute illness and chronic health evaluation score II.
\end{abstract}

\section{Supplementary Information}

The online version contains supplementary material available at https://doi. org/10.1186/s13054-021-03764-6.

Additional file 1. The mixed linear analysis of OptTOx, OptMAP, upper and lower MAP bounds and MAP range for maintained CVR in the 23 factorial design groups.

\section{Acknowledgements}

COMACARE study group. Aarhus University Hospital: Thomas Birkelund, Susanne Ilkjaer and Hans Kirkegaard; Central Finland Central Hospital: Raili Laru-Sompa, Anni Pulkkinen, Mikko Reilama and Sinikka Tolmunen; Helsinki University Hospital: Minna Bäcklund, Jonna Heinonen, Johanna Hästbacka, Pekka Jakkula, Nina Lundbom, Marcus Norrgård, Marjatta Okkonen, Ville Pettilä, Markus B Skrifvars, Tarja Suhonen, Marjaana Tiainen, Tuukka Tikka, Marjut Timonen, Jussi Toppila, Miia Valkonen and Erika Wilkman; Jorvi Hospital: Teemu Hult and Tuomas Oksanen; Kuopio University Hospital: Stepani Bendel, Elina Halonen, Sari Rahikainen, Saija Rissanen and Eija Vaskelainen; North Karelia Central Hospital:Tanja Eiserbeck, Sirkku Heino, Helena Jyrkönen, Matti Reinikainen, Johanna Räsänen and Tero Surakka; Päijät-Häme Central Hospital:Talvikki Koskue, Petteri Kujala, Pekka Loisa and Marika Lähde; Tampere University Hospital: Jari Kalliomäki, Sari Karlsson, Atte Kukkurainen and Simo Varila.

\section{Authors' contributions}

$J$ analysed the results and was responsible for preparing the manuscript. AA, AP and PM designed the study, analysed the results and were major contributors in writing the manuscript. JT contributed to the study design, was responsible for the assessment of neurological outcomes at six months and reviewed the manuscript. MS designed the study, obtained funding, actively recruited patients and was a major contributor to the writing of the manuscript. KB and $\mathrm{HZ}$ performed blood biomarker measurements. EW, JH, MR and PL recruited patients for the study. All authors reviewed and approved the final manuscript.

\section{Funding}

Independent funding support has been received from the Finnish Medical Foundation, Medicinska Understödsföreningen Liv och Hälsa, Sigrid Juselius Stiftelse and Finska Läkaresällskapet. HZ is a Wallenberg Scholar supported by grants from the Swedish Research Council (\#2018-02532), the European Research Council (\#681712), and Swedish State Support for Clinical Research (\#ALFGBG-720931).

\section{Availability of data and materials}

The dataset consisting of de-identified participants' data is available from the corresponding author upon reasonable request.

\section{Declarations}

Ethics approval and consent to participate

The COMACARE study protocol was approved by the research ethics committees of the Northern Savo District, Finland (Decision No. 295/2015) and the Midtjylland region, Denmark (Decision No. 1-10-72-163-16). In addition, the trial protocol was approved by the institutional review board at each participating hospital.

\section{Consent for publication}

Not applicable.

\section{Competing interests}

HZ has served at scientific advisory boards for Eisai, Denali, Roche Diagnostics, Wave, Samumed, Siemens Healthineers, Pinteon Therapeutics, Nervgen, AZTherapies and CogRx, has given lectures in symposia sponsored by Cellectricon, Fujirebio, Alzecure and Biogen, and is a co-founder of Brain Biomarker Solutions in Gothenburg AB (BBS), which is a part of the GU Ventures Incubator Program (outside submitted work). Markus Skrifvars reports a lecture fee and travel grant from BARD Medical (Ireland). Erika Wilkman reports an external research support agreement (Research-Devices Grant, INVOS) with Medtronic (Covidien Ag).

\section{Author details}

${ }^{1}$ Department of Anaesthesiology, Intensive Care and Pain Medicine, University of Helsinki and Helsinki University Hospital, Meilahden SairaalaHaartmaninkatu 4, 000290 Helsinki, Finland. ${ }^{2}$ Intensive Care Unit, Liverpool Hospital, South Western Sydney Local Health District, Sydney, Australia. ${ }^{3}$ Faculty of Medicine, The University of New South Wales, Sydney, Australia. ${ }^{4}$ Faculty of Medicine and Health Sciences, Macquarie University, Sydney, Australia. ${ }^{5}$ Department of Anaesthesiology and Intensive Care, University of Eastern Finland and Kuopio University Hospital, Kuopio, Finland. ${ }^{6}$ Dept of Anaesthesia, John Hunter Hospital, Newcastle, NSW, Australia. ${ }^{7}$ Department of Intensive Care, PäijätHäme Central Hospital, Lahti, Finland. ${ }^{8}$ Department of Neurology, University of Helsinki and Helsinki University Hospital, Helsinki, Finland. ${ }^{9}$ Aarhus University Hospital, Aarhus, Denmark. ${ }^{10}$ Department of Psychiatry and Neurochemistry, Institute of Neuroscience and Physiology, The Sahlgrenska Academy at the University of Gothenburg, Mölndal, Sweden. ${ }^{11}$ Clinical Neurochemistry Laboratory, Sahlgrenska University Hospital, Mölndal, Sweden. ${ }^{12}$ DUK Dementia Research Institute at UCL, London, UK. ${ }^{13}$ Department of Neurodegenerative Disease, UCL Institute of Neurology, London, UK. ${ }^{14}$ Department of Emergency Care and Services, Helsinki University Hospital and University of Helsinki, Helsinki, Finland.

Received: 2 June 2021 Accepted: 9 September 2021 Published online: 28 September 2021

\section{References}

1. Lemiale V, Dumas F, Mongardon N, Giovanetti O, Charpentier J, Chiche JD, Carli P, Mira JP, Nolan J, Cariou A. Intensive care unit mortality after cardiac arrest: the relative contribution of shock and brain injury in a large cohort. Intensive Care Med. 2013;39(11):1972-80.

2. Bisschops LL, Hoedemaekers CW, Simons KS, van der Hoeven JG. Preserved metabolic coupling and cerebrovascular reactivity during mild hypothermia after cardiac arrest. Crit Care Med. 2010;38(7):1542-7.

3. van den Brule JMD, van der Hoeven JG, Hoedemaekers CWE. Cerebral perfusion and cerebral autoregulation after cardiac arrest. Biomed Res Int. 2018;2018:4143636

4. Pham P, Bindra J, Chuan A, Jaeger M, Aneman A. Are changes in cerebrovascular autoregulation following cardiac arrest associated with neurological outcome? Results of a pilot study. Resuscitation. 2015;96:192-8.

5. Ameloot K, Genbrugge C, Meex I, Jans F, Boer W, Vander Laenen M, Ferdinande B, Mullens W, Dupont M, Dens J, et al. An observational nearinfrared spectroscopy study on cerebral autoregulation in post-cardiac 
arrest patients: time to drop "one-size-fits-all" hemodynamic targets? Resuscitation. 2015;90:121-6.

6. Sekhon MS, Gooderham P, Menon DK, Brasher PMA, Foster D, Cardim D, Czosnyka M, Smielewski P, Gupta AK, Ainslie PN, et al. The burden of brain hypoxia and optimal mean arterial pressure in patients with hypoxic ischemic brain injury after cardiac arrest. Crit Care Med. 2019;47(7):960-9.

7. Willie CK, Tzeng YC, Fisher JA, Ainslie PN. Integrative regulation of human brain blood flow. J Physiol. 2014;592(5):841-59.

8. Donnelly J, Budohoski KP, Smielewski P, Czosnyka M. Regulation of the cerebral circulation: bedside assessment and clinical implications. Crit Care. 2016;20(1):129.

9. Steiner LA, Pfister D, Strebel SP, Radolovich D, Smielewski P, Czosnyka M. Near-infrared spectroscopy can monitor dynamic cerebral autoregulation in adults. Neurocrit Care. 2009;10(1):122-8.

10. Diedler J, Zweifel C, Budohoski KP, Kasprowicz M, Sorrentino E, Haubrich C, Brady KM, Czosnyka M, Pickard JD, Smielewski P. The limitations of nearinfrared spectroscopy to assess cerebrovascular reactivity: the role of slow frequency oscillations. Anesth Analg. 2011;113(4):849-57.

11. Brady K, Joshi B, Zweifel C, Smielewski P, Czosnyka M, Easley RB, Hogue CW Jr. Real-time continuous monitoring of cerebral blood flow autoregulation using near-infrared spectroscopy in patients undergoing cardiopulmonary bypass. Stroke. 2010;41(9):1951-6.

12. Zweifel C, Dias C, Smielewski P, Czosnyka M. Continuous time-domain monitoring of cerebral autoregulation in neurocritical care. Med Eng Phys. 2014;36(5):638-45.

13. Rivera-Lara L, Geocadin R, Zorrilla-Vaca A, Healy R, Radzik BR, Palmisano C, White MA, Sha D, Ponce-Mejia L, Brown C, et al. Near-infrared spectroscopyderived cerebral autoregulation indices independently predict clinical outcome in acutely III comatose patients. J Neurosurg Anesthesiol. 2020;32(3):234-41.

14. Zeiler FA, Donnelly J, Calviello L, Smielewski P, Menon DK, Czosnyka M. Pressure autoregulation measurement techniques in adult traumatic brain injury, part II: a scoping review of continuous methods. J Neurotrauma. 2017;34(23):3224-37.

15. Sekhon MS, Smielewski P, Bhate TD, Brasher PM, Foster D, Menon DK, Gupta AK, Czosnyka M, Henderson WR, Gin K, et al. Using the relationship between brain tissue regional saturation of oxygen and mean arterial pressure to determine the optimal mean arterial pressure in patients following cardiac arrest: a pilot proof-of-concept study. Resuscitation. 2016;106:120-5.

16. Jakkula P, Reinikainen M, Hastbacka J, Pettila V, Loisa P, Karlsson S, LaruSompa R, Bendel S, Oksanen T, Birkelund T, et al. Targeting low- or highnormal carbon dioxide, oxygen, and mean arterial pressure after cardiac arrest and resuscitation: study protocol for a randomized pilot trial. Trials. 2017;18(1):507.

17. Jakkula P, Pettila V, Skrifvars MB, Hastbacka J, Loisa P, Tiainen M, Wilkman E, Toppila J, Koskue T, Bendel S, et al. Targeting low-normal or high-normal mean arterial pressure after cardiac arrest and resuscitation: a randomised pilot trial. Intensive Care Med. 2018;44(12):2091-101.

18. Jakkula P, Reinikainen M, Hastbacka J, Loisa P, Tiainen M, Pettila V, Toppila J, Lahde M, Backlund M, Okkonen M, et al. Targeting two different levels of both arterial carbon dioxide and arterial oxygen after cardiac arrest and resuscitation: a randomised pilot trial. Intensive Care Med. 2018:44(12):2112-21.

19. Aneman A, Laurikalla J, Pham P, Wilkman E, Jakkula P, Reinikainen M, Toppila J, Skrifvars MB. Cerebrovascular autoregulation following cardiac arrest: protocol for a post hoc analysis of the randomised COMACARE pilot trial. Acta Anaesthesiol Scand. 2019;63(9):1272-7.

20. Aries MJ, Czosnyka M, Budohoski KP, Steiner LA, Lavinio A, Kolias AG, Hutchinson PJ, Brady KM, Menon DK, Pickard JD, et al. Continuous determination of optimal cerebral perfusion pressure in traumatic brain injury. Crit Care Med. 2012;40(8):2456-63.

21. Wihersaari L, Ashton NJ, Reinikainen M, Jakkula P, Pettila V, Hastbacka J, Tiainen M, Loisa P, Friberg H, Cronberg T, et al. Neurofilament light as an outcome predictor after cardiac arrest: a post hoc analysis of the COMACARE trial. Intensive Care Med. 2021;47(1):39-48.

22. Cummins RO, Chamberlain DA, Abramson NS, Allen M, Baskett PJ, Becker L, Bossaert L, Delooz HH, DickWF, Eisenberg MS et al: Recommended guidelines for uniform reporting of data from out-of-hospital cardiac arrest: the Utstein Style. A statement for health professionals from a task force of the American Heart Association, the European Resuscitation Council, the Heart and Stroke Foundation of Canada, and the Australian Resuscitation Council. Circulation 1991, 84(2):960-975.

23. Slessarev M, Mahmoud O, McIntyre CW, Ellis CG: Cerebral blood flow deviations in critically ill patients: potential insult contributing to ischemic and hyperemic injury. Front Med (Lausanne) 2020, 7:615318.

24. Lazaridis C. Cerebral autoregulation: the concept the legend the promise. Neurocrit Care. 2021:34(3):717-9.

25. Rivera-Lara L, Zorrilla-Vaca A, Geocadin RG, Healy RJ, Ziai W, Mirski MA. Cerebral autoregulation-oriented therapy at the bedside: a comprehensive review. Anesthesiology. 2017;126(6):1187-99.

26. Minhas JS, Panerai RB, Swienton D, Robinson TG. Feasibility of improving cerebral autoregulation in acute intracerebral hemorrhage (BREATHEICH) study: results from an experimental interventional study. Int J Stroke. 2020;15(6):627-37.

27. Koyama Y. Endothelin systems in the brain: involvement in pathophysiological responses of damaged nerve tissues. Biomol Concepts. 2013;4(4):335-47.

28. Pesek M, Kibler K, Easley RB, Mytar J, Rhee C, Andropolous D, Brady K. The upper limit of cerebral blood flow autoregulation is decreased with elevations in intracranial pressure. Acta Neurochir Suppl. 2016;122:229-31.

29. Koide M, Ferris HR, Nelson MT, Wellman GC: Impaired cerebral autoregulation after subarachnoid hemorrhage: a quantitative assessment using a mouse model. Front Physiol 2021, 12:688468.

30. Chan B, Aneman A. A prospective, observational study of cerebrovascular autoregulation and its association with delirium following cardiac surgery. Anaesthesia. 2019;74(1):33-44.

31. Czosnyka M, Hutchinson P, Smielewski P. Treatment targets based on autoregulation parameters in neurocritical care patients. Curr Opin Crit Care. 2020;26(2):109-14.

32. Skrifvars MB, Aneman A, Ameloot K. Individualized blood pressure targets during postcardiac arrest intensive care. Curr Opin Crit Care. 2020;26(3):259-66.

33. Tan CO. Defining the characteristic relationship between arterial pressure and cerebral flow. J Appl Physiol (1985) 2012, 113(8):1194-1200.

34. Nolan JP, Sandroni C, Bottiger BW, Cariou A, Cronberg T, Friberg H, Genbrugge C, Haywood K, Lilja G, Moulaert VRM, et al. European Resuscitation Council and European Society of Intensive Care Medicine Guidelines 2021 post-resuscitation care. Resuscitation. 2021;161:220-69.

35. Drummond JC. Blood pressure and the brain: How low can you go? Anesth Analg. 2019;128(4):759-71.

36. Lassen NA. Cerebral blood flow and oxygen consumption in man. Physiol Rev. 1959;39(2):183-238.

37. Buunk G, van der Hoeven JG, Meinders AE. Cerebral blood flow after cardiac arrest. Neth J Med. 2000;57(3):106-12.

38. Cohan SL, Mun SK, Petite J, Correia J. Tavelra Da Silva AT, Waldhorn RE: Cerebral blood flow in humans following resuscitation from cardiac arrest. Stroke. 1989:20(6):761-5.

39. Lemiale V, Huet O, Vigue B, Mathonnet A, Spaulding C, Mira JP, Carli P, Duranteau J, Cariou A. Changes in cerebral blood flow and oxygen extraction during post-resuscitation syndrome. Resuscitation. 2008;76(1):17-24.

40. Peng A, Chua MJ, Chan B, Jaeger M, Aneman A, Chuan A. Tissue oxygenation indices of cerebrovascular autoregulation in healthy volunteers: a comparison of two NIRS devices. Neurol Res. 2020:42(10):897-903.

41. Hoiland RL, Sekhon MS, Cardim D, Wood MD, Gooderham P, Foster D, Griesdale $D E$. Lack of agreement between optimal mean arterial pressure determination using pressure reactivity index versus cerebral oximetry index in hypoxic ischemic brain injury after cardiac arrest. Resuscitation. 2020;152:184-91.

42. Kooi EMW, Verhagen EA, Elting JWJ, Czosnyka M, Austin T, Wong FY, Aries $\mathrm{MJH}$. Measuring cerebrovascular autoregulation in preterm infants using near-infrared spectroscopy: an overview of the literature. Expert Rev Neurother. 2017;17(8):801-18.

43. Rivera-Lara L, Geocadin R, Zorrilla-Vaca A, Healy R, Radzik BR, Palmisano C, Mirski M, Ziai WC, Hogue C. Validation of near-infrared spectroscopy for monitoring cerebral autoregulation in comatose patients. Neurocrit Care. 2017:27(3):362-9.

44. Caccioppola A, Carbonara M, Macri M, Longhi L, Magnoni S, Ortolano F, Triulzi F, Zanier ER, Zoerle T, Stocchetti N. Ultrasound-tagged near-infrared spectroscopy does not disclose absent cerebral circulation in brain-dead adults. Br J Anaesth. 2018;121(3):588-94.

45. Sekhon MS, Ainslie PN, Menon DK, Thiara SS, Cardim D, Gupta AK, Hoiland RL, Gooderham P, Griesdale DE. Brain hypoxia secondary to diffusion 
limitation in hypoxic ischemic brain injury postcardiac arrest. Crit Care Med. 2020;48(3):378-84.

46. Goodson CM, Rosenblatt K, Rivera-Lara L, Nyquist P, Hogue CW. Cerebral blood flow autoregulation in sepsis for the intensivist: why its monitoring may be the future of individualized care. J Intensive Care Med. 2018;33(2):63-73.

47. Nakano M, Nomura Y, Whitman G, Sussman M, Schena S, Kilic A, Choi CW, Akiyoshi K, Neufeld KJ, Lawton J, et al. Cerebral autoregulation in the operating room and intensive care unit after cardiac surgery. Br J Anaesth 2021;126(5):967-74

48. Zweifel C, Castellani G, Czosnyka M, Carrera E, Brady KM, Kirkpatrick PJ, Pickard JD, Smielewski P. Continuous assessment of cerebral autoregulation with near-infrared spectroscopy in adults after subarachnoid hemorrhage. Stroke. 2010;41(9):1963-8.

49. Highton D, Ghosh A, Tachtsidis I, Panovska-Griffiths J, Elwell CE, Smith M. Monitoring cerebral autoregulation after brain injury: multimodal assessment of cerebral slow-wave oscillations using near-infrared spectroscopy. Anesth Analg. 2015;121(1):198-205.

\section{Publisher's Note}

Springer Nature remains neutral with regard to jurisdictional claims in published maps and institutional affiliations.
Ready to submit your research? Choose BMC and benefit from:

- fast, convenient online submission

- thorough peer review by experienced researchers in your field

- rapid publication on acceptance

- support for research data, including large and complex data types

- gold Open Access which fosters wider collaboration and increased citations

- maximum visibility for your research: over $100 \mathrm{M}$ website views per year

At BMC, research is always in progress.

Learn more biomedcentral.com/submissions 